Rabaska

Revue d'ethnologie de l'Amérique française

\title{
Programme de français
}

Program in French Studies

\section{Cynthia Fox}

Volume 6, 2008

URI : https://id.erudit.org/iderudit/000197ar

DOI : https://doi.org/10.7202/000197ar

Aller au sommaire du numéro

Éditeur(s)

Société québécoise d'ethnologie

ISSN

1703-7433 (imprimé)

1916-7350 (numérique)

Découvrir la revue

Citer ce document

Fox, C. (2008). Programme de français. Rabaska, 6, 277-279.

https://doi.org/10.7202/000197ar d'utilisation que vous pouvez consulter en ligne.

https://apropos.erudit.org/fr/usagers/politique-dutilisation/ 


\section{Programme de français / Program in French Studies}

Department of Languages, Literatures and Cultures

Humanities 325

University at Albany, State University of New-York

1400 Washington Avenue

Téléphone : (518) 442-4102

Albany, NY 12222

Courriel : cf301@albany.edu

\section{A. Le projet «le français franco-américain »}

Entre 2001 et 2005, Cynthia Fox et sa collaboratrice Jane Smith de l'Université $\mathrm{du}$ Maine ont entrepris un projet de recherche en sociolinguistique portant sur le français des Franco-Américains du nord-est des États-Unis. Subventionné par la National Science Foundation, le projet a abouti à la constitution d'un corpus basé sur des entretiens faits auprès de plus de deux cent cinquante locuteurs francophones répartis selon l'âge et le sexe dans huit localités : Van Buren, Waterville et Biddeford (Maine), Berlin (New-Hampshire), Southbridge et Gardner (Massachusetts), Bristol (Connecticut) et Woonsocket (Rhode-Island). Le choix de ces communautés s'est fait en considérant l'hypothèse de C. Fox et L. Charbonneau selon laquelle il existe en français franco-américain une variation linguistique intercommunautaire qui repose sur deux axes géographiques. Le long d'un axe est-ouest, elle serait le résultat de la « migration en chaîne » qui a donné naissance à la franco-américanie et ferait ainsi écho aux grandes divisions dialectales franco-canadiennes et acadiennes. Le long d'un axe nord-sud, elle serait le fruit de la diversité des situations du français. Ainsi, les communautés sélectionnées se distinguent l'une de l'autre par les origines de la population d'ascendance « française » et par la proportion de la population parlant le français à la maison. L'interview typique dure entre 60 et 90 minutes et comprend une série de questions sur l'histoire familiale et les rapports avec la langue et la culture francophone. Les 250 heures d'enregistrements sonores ont été transcrites ; les transcriptions comprennent plus de trois mille pages informatisées.

\section{Diffusion de la recherche (à partir de l'Université à Albany).}

En plus des publications faites en collaboration avec J. Smith, C. Fox et ses étudiants Louis Stelling, Véronique Martin, Geneviève Fortin, Mariame Bagaté, Jody Lemery et Nadja Wyvekens, ont déjà complété sous forme de conférences et articles, plusieurs analyses qui traitent des questions liées les unes aux autres : 1) la situation du français franco-américain à l'heure actuelle ; 2) le maintien ou la perte des traits franco-canadiens et acadiens ; 3 ) les 
conséquences linguistiques du contact avec l'anglais et de l'emploi réduit du français ; et 4) le franco-américain à l'intérieur du dynamisme du français nord-américain.

Parmi les activités les plus récentes, C. Fox a préparé une exposition itinérante Le Français en Nouvelle-Angleterre/The French Language in New England. Notes from the Franco-American French Project dont l'objectif est de diffuser au public, franco-américain surtout, les informations quant au statut et à l'emploi du français et aux attitudes linguistiques chez les FrancoAméricains à l'heure actuelle. L'exposition a été présentée pour la première fois au mois de juillet 2007 à la Jacob Edwards Memorial Library à Southbridge; on a pu y incorporer des documents d'archives pertinents à l'histoire de la communauté franco-américaine de Southbridge. En avril 2008, l'exposition a été présentée au Center for Foreign Languages, Literatures and Cultures (Weston Hall) de Williams College (Massachusetts). L'exposition a inclu des documents sur la communauté franco-américaine de Williamstown prêtés par la bibliothèque de l'université et par la Williamstown House of Local History. Dans le cadre de chacune de ces expositions, C. Fox a également prononcé une conférence, laquelle a précipité des discussions animées parmi un auditoire largement franco-américain.

$\mathrm{Au}$ mois de juillet 2008, L. Stelling a soutenu la première thèse de $3^{\mathrm{e}}$ cycle basée sur ce corpus : «Morphosyntactic Variation and Language Shift in Two Franco-American Communities ».

\section{B. L'Encyclopédie du patrimoine culturel de l'Amérique française} Éloïse Brière travaille à ce projet, dirigé par Laurier Turgeon de l'Université Laval, avec les autres membres du comité scientifique depuis l'automne 2006. En particulier, avec Kristen Neel et Kimberly Lamay, étudiantes de $3^{\mathrm{e}}$ cycle en histoire, l'équipe œuvre avec Martin Fournier de l'Université Laval pour ce qui concerne le patrimoine étatsunien et new-yorkais. Deux autres membres du Programme de français y rédigent des articles : J.-F. Brière sur le patrimoine « terreneuvas » en France et C. Fox sur le français des Franco-Américains. L'encyclopédie est désormais accessible à l'adresse www.amerique francaise.org.

\section{Hudson-Fulton-Champlain quadricentennial}

Actuellement en cours, la mise à jour du guide bilingue J'aime le N.Y./I Love N.Y : a bilingual guide to the French heritage of New York State, sous l'égide d'Éloïse Brière avec Kimberly Lamay et Kristin Bini, étudiantes de $3^{\mathrm{e}}$ cycle, devrait se terminer pour la rentrée. Ce livret, appuyé par des octrois de différents organismes, en particulier le chapitre local de l'American 
Association of Teachers of French (AATF), est réédité pour fêter le $400^{\circ}$ anniversaire des découvertes de Samuel de Champlain ainsi que de Henry Hudson.

Cynthia Fox 